\title{
Antimicrobial activity of different disinfectants against cariogenic microorganisms
}

\section{Esra UZER CELIK(a) Ayse Tugce TUNAC(a) Mustafa ATES ${ }^{(b)}$ Bilge Hakan SEN(c)}

(a) Izmir Katip Celebi University, Faculty of Dentistry, Department of Restorative Dentistry, Izmir, Turkey.

(b) Ege University, Faculty of Science, Department of Biology, Division of Basic and Industrial Microbiology, Izmir, Turkey.

(c) Private Practice, Izmir, Turkey.

Declaration of Interests: The authors certify that they have no commercial or associative interest that represents a conflict of interest in connection with the manuscript.

\section{Corresponding Author:}

Esra Uzer Celik

E-mail: esrauzer@yahoo.com

DOI: 10.1590/1807-3107BOR-2016.vol30.0125

Submitted: Jan 15, 2016

Accepted for publication: Jul 15, 2016

Last revision: Sep 15, 2016

\begin{abstract}
The aim of this study was to assess the in vitro antimicrobial effects of chlorhexidine digluconate (CHX), polyhexamethylene biguanide (PHBM), and octenidine dihydrochloride (OCT) on cariogenic microorganisms by using their minimum inhibitory concentration (MIC) and minimum bactericidal concentration (MBC). CHX, PHBM, and OCT were diluted in distilled water to the final test concentrations. Using the in-tube dilution method, Streptococcus mutans, Lactobacillus acidophilus, Lactobacillus rhamnosus, and Actinomyces viscosus were cultivated on blood agar and Mueller-Hinton broth (MHB) at $37^{\circ} \mathrm{C}$ for $48 \mathrm{~h}$. They were read using a spectrophotometer to detect MIC. To determine MBC, samples in the range of the turbidity threshold after $24 \mathrm{~h}$ were transferred onto blood agar and evaluated for growth after $24 \mathrm{~h}$. Different MICs and MBCs were observed in all disinfectants against each microorganism. The lowest MIC and MBC against $S$. mutans $(60 \mathrm{mg} / \mathrm{L})$ were obtained from PHBM. The lowest values against L. rhamnosus ( $15 \mathrm{mg} / \mathrm{L}, 30 \mathrm{mg} / \mathrm{L})$, A. viscosus (30 mg/L), and L. acidophilus (15 mg/L, $30 \mathrm{mg} / \mathrm{L})$ were determined by OCT. PHBM and OCT have the potential to be replaced with $\mathrm{CHX}$ because they were effective against cariogenic microorganisms.
\end{abstract}

Keywords: Octenidine; Polyhexamethylene Biguanide; Chlorhexidine Gluconate.

\section{Introduction}

Dental caries is a localized and transmissible pathological infectious process that results in the destruction of hard dental tissues. ${ }^{1}$ The elimination of cariogenic microorganisms is one of the crucial factors for the prevention of primary or residual caries lesions. ${ }^{2}$ Recent research shows that Streptococcus mutans, Lactobacillus acidophilus, Actinomyces viscosus, and L. rhamnosus are the most common cariogenic microorganisms. ${ }^{3,45}$ S. mutans is the main etiological agent in dental caries. ${ }^{6}$ It is associated with the initiation of caries and is also isolated both from enamel carious lesions and hidden dentin caries. ${ }^{7}$ Lactobacillus is a group of bacteria that occurs at high levels in deep dentin caries. ${ }^{8}$ The analysis shows that among the genus Lactobacillus, L. acidophilus is most prevalent, and L. paracasei, L. rhamnosus, and L. fermentum are also present in deep caries lesions and promote caries progression. ${ }^{8,9}$ Furthermore, the fact that L. rhamnosus constitutes the dominant species in carious dentin both in deciduous and permanent teeth has been supported 
by numerous authors using biochemical or reliable genetically-based methods. ${ }^{2,10,11,12,13,14}$ In addition to Lactobacillus species, anaerobic conditions have resulted in the isolation of Actinomyces species from dentin lesions. ${ }^{15}$

To reduce the potential of primary or residual caries and enhance the postoperative sensitivity, antibacterial agents may be chosen according to their ability to reduce or eliminate the possibility of existing bacteria. Thus, the use of antimicrobial solutions as an oral rinse or a cavity disinfectant for reducing cariogenic microorganisms according to the target of the application has been recommended. Chlorhexidine digluconate $(\mathrm{CHX})$ is a commonly used antimicrobial agent because of its ability to significantly reduce the levels of cariogenic microorganisms. ${ }^{16-18}$

However, CHX had adverse effects, including staining of the teeth and tongue, mucosal soreness, and desquamation; temporary taste disturbances; hypersensitivity; and selective disturbance of the microbial balance within the oral ecosystem. ${ }^{19}$ Previous studies have shown that $\mathrm{CHX}$ was cytotoxic to human fibroblasts via the inhibition of protein synthesis. ${ }^{20}$ In addition, the resistance of L. rhamnosus to $\mathrm{CHX}$ therapy was also reported. ${ }^{21}$ Therefore, antimicrobial agents, such as octenidine dihydrochloride (OCT) and polyhexamethylene biguanide (PHMB) have been investigated as alternatives to $\mathrm{CHX}$ because of their superior microbicidal activity and lower cytotoxicity than $\mathrm{CHX}^{22,23,24,25}$

OCT is an antiseptic agent recently used for the management of skin burns, wounds, and as a mouth rinse. OCT belongs to the bipyridines, carrying two cationic active centers per molecule, and demonstrates the broad-spectrum antimicrobial effects on both gram-positive and gram-negative bacteria, fungi, and several viral species. ${ }^{26}$ The bactericidal and fungicidal effects are primarily achieved by interfering with the cell wall and membranes of such microbes. Previous studies have shown that the efficacy of OCT against dental plaque-associated bacteria (e.g., S. mutans and A. viscosus) was comparable to that of CHX. ${ }^{24,27}$

PHMB is a type of modern antiseptic that combines a broad antimicrobial spectrum with low toxicity, high tissue compatibility, no reported adsorption, and is used as a solution, gel, ointment, or foam. As such, it is one of the most promising antiseptic substances. ${ }^{25}$

Although some studies have been published concerning the antimicrobial properties of OCT on S. mutans and A. viscosus as well as that of PHMB on S. mutans, ${ }^{28,29}$ there is a lack of studies regarding their antibacterial activity on other essential cariogenic microorganisms (e.g., L. rhamnosus and L. acidophilus). Therefore, the aim of the present study was to assess the in vitro antimicrobial effects of $\mathrm{CHX}, \mathrm{OCT}$, and PHMB on cariogenic microorganisms using both their minimum inhibitory concentration (MIC) and minimum bactericidal concentration (MBC).

\section{Methodology}

The experiments were performed at the Microbiology Laboratory in the Department of Biology, Faculty of Science, Ege University. Culture media brain-heart infusion (BHI) (Difco, Detroit, MI, USA) broth and agar were made. The tubes and the plates were sterilized in an autoclave, tested for sterility, and kept under refrigeration until use.

CHX (Drogsan, Ankara, Turkey), PHMG (Mertsel Ilac, Izmir, Turkey), and OCT (Schülke \& Mayr GmbH, Norderstedt, Germany) were obtained as solutions and diluted in water of standardized hardness (WSH, according to DIN EN 1040) to the test concentrations. The initial concentrations of OCT and PHMB were $0.2 \%(2,000 \mathrm{mg} / \mathrm{L})$, and $2 \%(20,000 \mathrm{mg} / \mathrm{L})$ for CHX. The tube dilution method was used for determining MIC and MBC of the antimicrobial agents against the selected microorganisms.

In this study, S. mutans (ATCC 25175), L. acidophilus (ATCC 4356), A. viscosus (ATCC 15987), and L. rhamnosus (ATCC 7469) were used; all were previously frozen. All bacterial strains were obtained from the American-type culture collection.

The microorganisms were reactivated in sterile $\mathrm{BHI}$ broth and incubated at $37^{\circ} \mathrm{C}$ in a carbon dioxide incubator (SANYO Electric Biomedical Co., Ltd., Osaka, Japan) at $5 \% \mathrm{CO}_{2}$. After $48 \mathrm{~h}$ of culture growth, the Gram staining was used and the cultures were replated to verify their purity. The microorganisms were transferred to the broth media and their absorbance indexes were verified hourly using 
a spectrophotometer at a wavelength of $540 \mathrm{~nm}$. Bacterial suspensions equal to the No. 0.5 McFarland standard were prepared.

Ten sterile test tubes were collected and $1 \mathrm{~mL}$ of sterile tryptic soy broth (TSB) was added to each tube. Then, $1 \mathrm{~mL}$ of each solution with specified dilutions was prepared using the serial dilution (1:2) method and added to each of the tubes. A bacterial suspension of $1.5 \times 10^{8} \mathrm{CFU}$ equal to the No. $0.5 \mathrm{McF}$ arland standard was prepared from the standard strains.

A $1 \mathrm{~mL}$ volume of the dilute suspension was added to each set of eight tubes that contained the TSB medium and solution. After the bacterial suspension was added to the test tubes, they were placed in a carbon dioxide incubator (to provide $5 \% \mathrm{CO}_{2}$ ) and were incubated at $37^{\circ} \mathrm{C}$ for $24-48 \mathrm{~h}$. After this period had elapsed, the tubes were examined for the presence of turbidity, which indicated microbial growth. The last tube, or the last dilution of solutions at which turbidity was not observed, was considered MIC of the respective solutions for certain microorganisms. MIC of each of the three solutions was then compared for the ability to inhibit microbial growth. After a $24 \mathrm{~h}$ incubation, the tubes without turbidity (transparent), which indicated the inhibition of bacterial growth by the respective solutions, were transferred to a solid medium (TSA agar) and evaluated for microbial growth to determine the MBC of the solutions. The last tube, which was negative regarding the presence of cultures on a solid medium, indicated MBC of the solutions. This procedure was performed for all bacterial strains. The experiment was performed in triplicate.

\section{Results}

All disinfectants tested had bactericidal and bacteriostatic effects on the cariogenic microorganisms tested in this study. However, different MICs and MBCs were observed in all disinfectants against each microorganism (Figure).

The lowest MIC values against $S$. mutans were obtained from CHX (70 mg/L) and PHBM (60 mg/L), while MIC of OCT $(120 \mathrm{mg} / \mathrm{L})$ was two times greater than that of CHX and PHBM. The lowest MBC was obtained from PHBM $(60 \mathrm{mg} / \mathrm{L})$, while MBC of CHX $(150 \mathrm{mg} / \mathrm{L})$ and OCT $(120 \mathrm{mg} / \mathrm{L})$ was nearly twice that of PHBM.

The lowest MIC against L. rhamnosus was achieved by OCT and PHBM (15 mg/L), while MIC of CHX $(150 \mathrm{mg} / \mathrm{L})$ was ten times greater than OCT and PHBM. The lowest MBC was determined by OCT and PHBM (30 mg/L), while MBC of CHX (150 mg/L) was five times greater than OCT and PHBM.

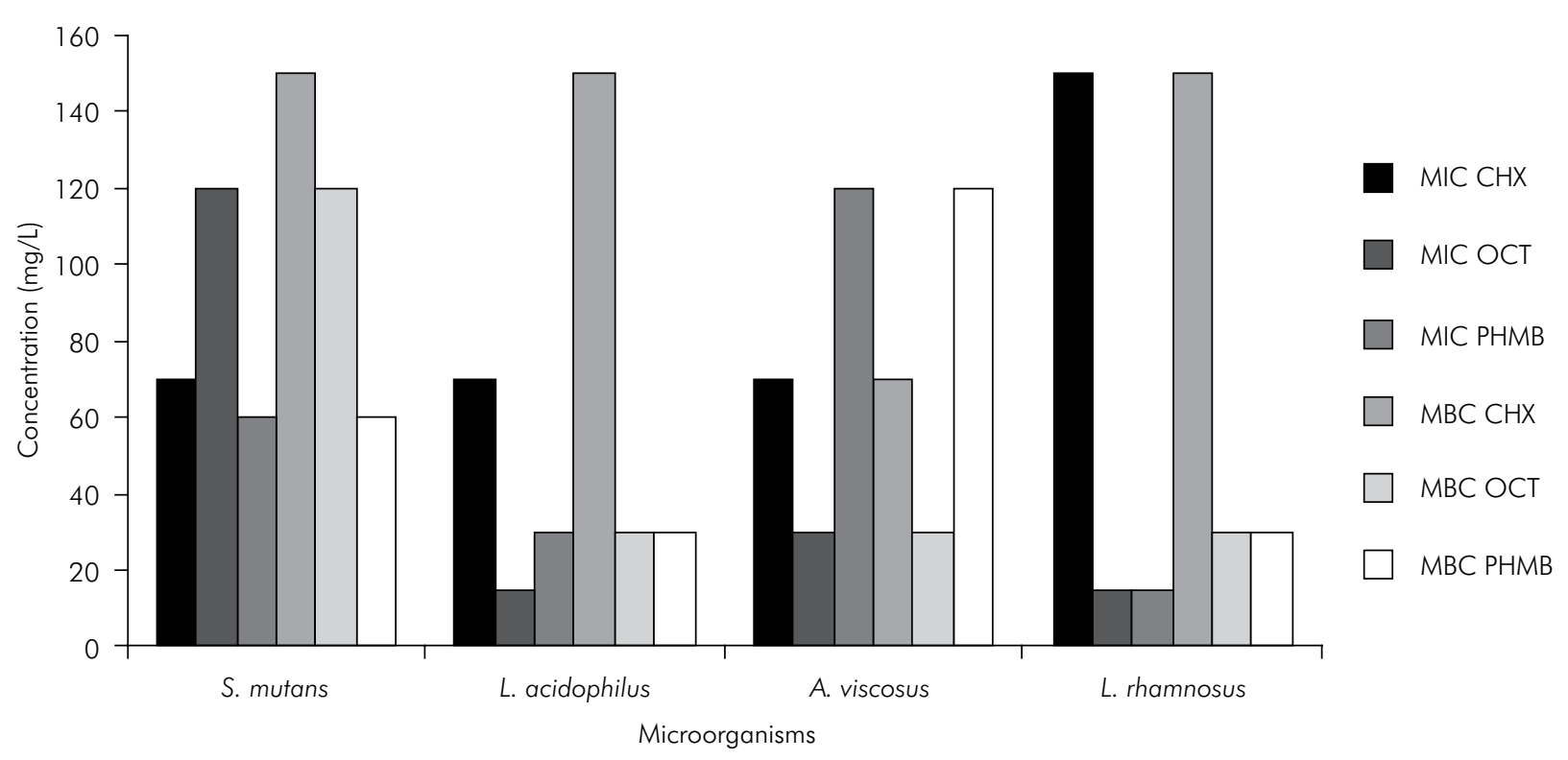

Figure. The minimum inhibitory concentrations (MICs) and minimum bactericidal concentrations (MBCs) of various antimicrobial agents. 
The lowest MIC against L. acidophilus was found to be OCT (15 mg/L), while MIC of PHMB ( $30 \mathrm{mg} / \mathrm{L}$ ) was two times and MIC of CHX (70 mg/L) was nearly four times greater than OCT. The lowest MBC was obtained from OCT and PHMB (30 mg/L), while MBC of CHX (150 mg/L) was five times greater than OCT and PHMB.

The lowest MIC and MBC against $A$. viscosus (30 mg/L) was determined by OCT, while MIC and $\mathrm{MBC}$ of $\mathrm{CHX}(70 \mathrm{mg} / \mathrm{L})$ were two times and MIC and MBC of PHBM $(120 \mathrm{mg} / \mathrm{L})$ were four times greater than OCT.

\section{Discussion}

MICs and MBCs of the antimicrobial agents investigated in the present study were determined using the microdilution test method. MICs are defined as the lowest concentration of an antimicrobial that will inhibit the visible growth of a microorganism after an overnight incubation and are considered the gold standard for determining the susceptibility of organisms to antimicrobials. On the other hand, MBCs are the lowest concentrations of an antimicrobial that will prevent the growth of an organism following a subculture on antimicrobial-free media. ${ }^{30} \mathrm{MBCs}$ are used for determining the potential resistance of an antimicrobial and making rational decisions in determining how successful an antimicrobial treatment is likely to be. ${ }^{30}$ However, MBC is more relevant than MIC for assessing the antibacterial activity of a solution and is also higher than MIC. ${ }^{31}$ In this study, the initial concentration of the tested solutions were different and are the commonly used concentrations for these solutions.

Three commonly used antimicrobial agents were tested. CHX is used at a concentration of $0.12 \%$ and $0.2 \%$ as oral rinses, and $2 \%$ as an endodontic irrigation solution and cavity disinfectant. ${ }^{32}$ Additionally, for $\mathrm{CHX}$ to be used as an anticarcinogenic agent, a $1 \%$ concentration in a gel formulation is available. ${ }^{33,34} \mathrm{OCT}$ is commonly used at a concentration of $0.1 \%-0.2 \%$ and PHMB is used at $0.2 \%$ as an antiseptic. $25,35,36$

It was demonstrated that all antiseptic solutions had both bacteriostatic and bactericidal effects against the test microorganisms, as CHX was used at $150 \mathrm{mg} / \mathrm{L}$ and OCT and PHMB were used at $120 \mathrm{mg} / \mathrm{L}$ in the present study. All of the bacterial groups that were chosen as the test microorganisms in this study were the most common cariogenic bacteria isolated from caries lesions. $3,4,5,7,8,9,15$ The antimicrobial effects of these agents against oral microorganisms, such as S. mutans, S. sanguinis, C. allbicans, and F. nucleatum were previously confirmed by Kocak et al. ${ }^{30}$ and Rohrer et al. ${ }^{37}$ However, the antibacterial effects of these agents on the other crucial microorganisms in caries progression (e.g., L. rhamnosus and L. acidophilus) were not assessed. The most important findings in the present study included the effectiveness of these antimicrobials against common cariogenic bacteria and MIC of these agents.

PHMB and CHX were both effective against all microorganisms tested; however, against Lactobacillus species and S. mutans, PHMB was effective at the same or slightly lower concentrations than $\mathrm{CHX}$. This finding is in accordance with Rohrer et al. ${ }^{37}$ who stated that the antimicrobial activity of PHMB was comparable to that of $\mathrm{CHX}$ against $S$. mutans and $S$. sanguinis. PHMB is a biguanide with effective antibacterial properties. The antibacterial effect is mediated by an increase in the permeability of the bacterial cell membrane, which leads to an osmotic imbalance and an outpouring of cytoplasm. Polyhexanides have a broad antibacterial spectrum, mainly against Staphylococcus aureus, Enterococcus faecalis, Bacillus subtilis, Enterobacter cloacae, and Streptococcus lactis. In addition to its effective antibacterial activity against the cariogenic microorganisms tested, the cytotoxicity of PHMB is low, and thus, the tissue compatibility is high. The local tolerability of PHMB is superior compared to other disinfectants, such as iodine, hydrogen peroxide, or $\mathrm{CHX}^{38}$

In the present study, OCT was found to be more effective than $\mathrm{CHX}$ at lower concentrations against each microorganism. Similarly, Kocak et al. ${ }^{30}$ and Dogan et al. ${ }^{38}$ found in their previous studies that OCT was more favorable than $\mathrm{CHX}$ regarding its antibacterial activity against $S$. mutans and Lactobacillus species, both in vitro and in vivo. OCT was originally developed as a potential broad-spectrum topical antimicrobial agent, ${ }^{39}$ and its use as an oral rinse has been reported to inhibit the development of dental plaque in both primates ${ }^{27}$ and in humans..$^{40,41}$ One recent study 
showed that a $0.1 \%$ OCT mouth rinse provided a statistically significant reduction of $39 \%$ of plaque, $50 \%$ of gingivitis, and $60 \%$ of gingival bleeding sites. ${ }^{42}$ Moreover, in an in vivo study, it was observed that $0.1 \%$ OCT had a significant effect on S. mutans in both 1 and 10 min time periods, and the antimicrobial efficiency was preserved even after $60 \mathrm{~min} .^{29}$

CHX, OCT, and PHMB were found to be effective against the most common cariogenic microorganisms in this study. However, their potential use in clinical procedures and their effect on biofilm formation,

\section{References}

1. Loesche WJ. Role of Streptococcus mutans in human dental decay. Microbiol Rev. 1986;50(4):353-80.

2. Bjørndal L, Larsen T. Changes in the cultivable flora in deep carious lesions following a stepwise excavation procedure. Caries Res. 2000;34(6):502-8. doi:10.1159/000016631

3. Takahashi N, Nyvad B. Caries ecology revisited: microbial dynamics and the caries process. Caries Res. 2008;42(6):409-18. doi:10.1159/000159604

4. Oda Y, Hayashi F, Okada M. Longitudinal study of dental caries incidence associated with Streptococcus mutans and Streptococcus sobrinus in patients with intellectual disabilities. BMC Oral Health. 2015;15(1):102. doi:10.1186/s12903-015-0087-6

5. Cura F, Palmieri A, Girardi A, Martinelli M, Scapoli L, Carinci F. Lab-Test ${ }^{\circledR}$ 4: dental caries and bacteriological analysis. Dent Res J (Isfahan). 2012;9(Suppl 2):139-41. doi:10.4103/1735-3327.109723

6. Anita P, Sivasamy S, Madan Kumar PD, Nanda Balan I, Ethiraj S. Streptococcus mutans and Lactobacillus acidophilus encourage the accumulation and adherence of plaque biofilm by metabolizing sucrose into sticky glucan. J Basic Clin Pharm. 2015;6(1):35-9. doi:10.4103/0976-0105.145777

7. Simón-Soro A, Mira A. Solving the etiology of dental caries. Trends Microbiol. 2015;23(2):76-82. doi:10.1016/j.tim.2014.10.010

8. Byun R, Nadkarni MA, Chhour KL, Martin FE, Jacques NA, Hunter N. Quantitative analysis of diverse Lactobacillus species present in advanced dental caries. J Clin Microbiol. 2004;42(7):3128-36. doi:10.1128/JCM.42.7.3128-3136.2004

9. Callaway A, Kostrzewa M, Willershausen B, Schmidt F, Thiede B, Küpper $\mathrm{H}$ et al. Identification of Lactobacilli from deep carious lesions by means of species-specific PCR and MALDI-TOF mass spectrometry. Clin Lab. 2013;59(11-12):1373-9. doi:10.7754/Clin.Lab.2013.121225 bacterial adhesion, and bond strength of adhesive systems should be investigated with future in vitro and in vivo studies.

\section{Conclusion}

The findings of the present study suggest that OCT and $\mathrm{PHMB}$ are significantly effective against cariogenic microorganisms at $120 \mathrm{mg} / \mathrm{L}$ concentrations. OCT and $\mathrm{PHMB}$ can be considered potential alternatives to $\mathrm{CHX}$ for reducing cariogenic microorganisms during antibacterial procedures.

10. Marchant S, Brailsford SR, Twomey AC, Roberts GJ, Beighton D. The predominant microflora of nursing caries lesions. Caries Res. 2001;35(6):397-406. doi:10.1159/000047482

11. Becker MR, Paster BJ, Leys EJ, Moeschberger ML, Kenyon SG, Galvin JL et al. Molecular analysis of bacterial species associated with childhood caries. J Clin Microbiol. 2002;40(3):1001-9. doi:10.1128/JCM.40.3.1001-1009.2002

12. Munson MA, Banerjee A, Watson TF, Wade WG. Molecular analysis of the microflora associated with dental caries. J Clin Microbiol. 2004;42(7):3023-9. doi:10.1128/JCM.42.7.3023-3029.2004

13. Wicht MJ, Haak R, Schütt-Gerowitt H, Kneist S, Noack MJ. Suppression of caries-related microorganisms in dentine lesions after short-term chlorhexidine or antibiotic treatment. Caries Res. 2004;38(5):436-41. doi:10.1159/000079624

14. Edwardsson S. Bacteriological studies on deep areas of carious dentine. Odontol Rev Suppl. 1974;32:1-143.

15. Botha SJ, Boy SC, Botha FS, Senekal R. Lactobacillus species associated with active caries lesions. J Dent Assoc S Afr 1998;53(1):3-6.

16. Obata J, Takeshita T, Shibata Y, Yamanaka W, Unemori M, Akamine A et al. Identification of the microbiota in carious dentin lesions using $16 \mathrm{~S}$ rRNA gene sequencing. PLoS One. 2014;9(8):e103712. doi:10.1371/journal.pone.0103712

17. Rijkom HM, Truin GJ, Hof MA. A meta-analysis of clinical studies on the caries-inhibiting effect of chlorhexidine treatment. J Dent Res. 1996;75(2):790-5. doi:10.1177/00220345960750020901

18. Emilson CG. Potential efficacy of chlorhexidine against mutans streptococci and human dental caries. J Dent Res.1994;73(3):682-91. doi:10.1177/00220345940730031401 
19. Walsh T, Oliveira-Neto JM, Moore D. Chlorhexidine treatment for the prevention of dental caries in children and adolescents. Cochrane Database Syst Rev. 2015;13(4):CD008457. doi:10.1002/14651858.CD008457.pub2

20. Goldschmidt P, Cogen R, Taubman S. Cytopathologic effects of chlorhexidine on human cells. J Periodontol. 1977;48(4):212-5. doi:10.1902/jop.1977.48.4.212

21. Pucher JJ, Daniel JC. The effects of chlorhexidine digluconate on human fibroblasts in vitro. J Periodontol. 1993;63(6):526-32. doi:10.1902/jop.1992.63.6.526

22. Epstein JB, McBride BC, Stevenson-Moore P, Merilees H, Spinelli J. The efficacy of chlorhexidine gel in reduction of Streptococcus mutans and Lactobacillus species in patients treated with radiation therapy. Oral Surg Oral Med Oral Pathol. 1991;71(2):172-8. doi:10.1016/0030-4220(91)90461-K

23. Müller G, Kramer A. Biocompatibility index of antiseptic agents by parallel assessment of antimicrobial activity and cellular cytotoxicity. J Antimicrob Chemother. 2008;61(6):1281-7. doi:10.1093/jac/dkn125

24. Tirali RE, Bodur H, Sipahi B, Sungurtekin E. Evaluation of the antimicrobial activities of chlorhexidine gluconate, sodium hypochlorite and octenidine hydrochloride in vitro. Aust Endod J. 2013;39(1):15-8. doi:10.1111/j.1747-4477.2010.00266.x

25. Decker EM, Weiger R, Wiech I, Heide PE, Brecx M. Comparison of antiadhesive and antibacterial effects of antiseptics on Streptococcus sanguinis. Eur J Oral Sci. 2003;111(2):144-8. doi:10.1034/j.1600-0722.2003.00025.x

26. Hübner NO, Kramer A. Review on the efficacy, safety and clinical applications of polihexanide, a modern wound antiseptic. Skin Pharmacol Physiol. 2010;23(suppl 1):17-27. doi:10.1159/000318264

27. Sedlock DM, Bailey DM. Microbicidal activity of octenidine hydrochloride, a new alkanediylbis[pyridine] germicidal agent. Antimicrob Agents Chemother. 1985;28(6):786-90. doi:10.1128/AAC.28.6.786

28. Slee AM, O'Connor JR, Bailey DM. Relationship between structure and antiplaque and antimicrobial activities for a series of bispyridines. Antimicrob Agents Chemother. 1983;23(4):531-5. doi:10.1128/AAC.23.4.531

29. Slee AM, O'Connor JR. In vitro antiplaque activity of octenidine dihydrochloride (WIN 41464-2) against preformed plaques of selected oral plaque-forming microorganisms. Antimicrob Agents Chemother. 1983;23(3):379-84. doi:10.1128/AAC.23.3.379

30. Kocak MM, Ozcan S, Kocak S, Topuz O, Erten H. Comparison of the efficacy of three different mouthrinse solutions in decreasing the level of streptococcus mutans in saliva. Eur J Dent. 2009;3(1):57-61.

31. Andrews JM. Determination of minimum inhibitory concentrations. J Antimicrob Chemother. 2001;48(suppl 1):5-16. doi:10.1093/jac/48.suppl_1.5
32. Peterson LR, Shanholtzer CJ. Tests for bactericidal effects of antimicrobial agents: technical performance and clinical relevance. Clin Microbiol Rev. 1992;5(4):420-32. doi:10.1128/CMR.5.4.420

33. Najafi MH, Taheri M, Mokhtari MR, Forouzanfar A, Farazi F, Mirzaee $\mathrm{M}$ et al. Comparative study of $0.2 \%$ and $0.12 \%$ digluconate chlorhexidine mouth rinses on the level of dental staining and gingival indices. Dent Res J (Isfahan). 2012;9(3):305-8.

34. Slot DE, Rosema NA, Hennequin-Hoenderdos NL, Versteeg PA, Van Der Velden U, Van Der Weijden GA. The effect of $1 \%$ chlorhexidine gel and $0.12 \%$ dentifrice gel on plaque accumulation: a 3-day non-brushing model. Int J Dent Hyg 2010;8(4):294-300. doi:10.1111/j.1601-5037.2010.00487.x

35. Maltz, M, Zickert I, Krasse B. Effect of intensive treatment with chlorhexidine on number of Streptococcus mutans in saliva. Scand J Dent Res. 1981;89(6):445-9.

36. Hübner NO, Siebert J, Kramer A. Octenidine dihydrochloride, a modern antiseptic for skin, mucous membranes and wounds. Skin Pharmacol Physiol 2010;23(5):244-58. doi:10.1159/000314699

37. Rohrer N, Widmer AF, Waltimo T, Kulik EM, Weiger R, Filipuzzi-Jenny E et al. Antimicrobial efficacy of 3 oral antiseptics containing octenidine, polyhexamethylene biguanide, or Citroxx: can chlorhexidine be replaced? Infect Control Hosp Epidemiol. 2010;31(7):733-9. doi:10.1086/653822

38. Dogan AA, Adiloglu AK, Onal S, Cetin ES, Polat E, Uskun $\mathrm{E}$ et al. Short-term relative antibacterial effect of octenidine dihydrochloride on the oral microflora in orthodontically treated patients. Int J Infect Dis. 2008;12(6):19-25. doi:10.1016/j.ijid.2008.03.013

39. Andrews JM. Determination of minimum inhibitory concentrations. J Antimicrob Chemother. 2001;48(Suppl 1):5-16. doi:10.1093/jac/48.suppl_1.5

40. Emilson CG, Bowen WH, Robrish SA, Kemp CW. Effect of the antibacterial agents octenidine and chlorhexidine on the plaque flora in primates. Scand J Dent Res 1981;89(5):384-92.

41. Pithon MM, Sant'Anna LI, Baião FC, Santos RL, Coqueiro RS, Maia LC. Assessment of the effectiveness of mouthwashes in reducing cariogenic biofilm in orthodontic patients: a systematic review. J Dent. 2015;43(3):297-308. doi:10.1016/j.jdent.2014.12.010

42. Patters MR, Anerud K, Trummel CL, Kornman KS, Nalbandian J, Robertson PB. Inhibition of plaque formation in humans by octenidine mouth rinse. J Periodontal Res. 1983;18(2):212-9. doi:10.1111/j.1600-0765.1983.tb00354 